\title{
Nanotechnology a Boon or a Curse: A Review
}

\author{
Manish Gunjan*, Rohayah BM and Turani T \\ Asia Metropolitan University, Malaysia
}

Submission: July 11, 2017; Published: August 09, 2017

*Corresponding author: Manish Gunjan, Senior Lecturer, Faculty of Medicine, Asia Metropolitan University, Johor Bahru, Malaysia, Tel: +60172960902; Email: manishgunjan1@gmail.com

\begin{abstract}
Nanotechnology is one of the latest technology which has been appreciated in several streams of science and technology. Nanotechnology is nothing but the fundamental understanding about how materials react or works at nano-scale. The first scientist who greatly believed that nanotechnology could have uses in medicine was Eric Drexler. He wanted to use nanotechnology to diagnose and treat injuries and disease, due to the molecules negligible size; he thought that nanotechnology may be able to help in surgery. Later there were several drug delivery systems, diagnostic devices etc came into market which brings a revolution in the field of medicine and medical practice. Hence the small but having greater future perspectives review was performed systematically.
\end{abstract}

Keywords: Nanotechnology; Nano-immunology; Photoprotection; Nanoparticles; Nanodiagnostic; Nanomedicine

\section{Introduction}

Nanotechnology means any technology on a nano-scale that has applications in the real world. Nanotechnology encompasses the production and application of physical, chemical, and biological systems at scales ranging from individual atoms or molecules to submicron dimensions, as well as the integration of the resulting nanostructures into larger systems. Nanotechnology is likely to have a profound impact on our economy and society in the early 21 st century, comparable to that of semiconductor technology, information technology, or cellular and molecular biology. Science and technology research in nanotechnology promises breakthroughs in areas such as materials and manufacturing, nano electronics, medicine and healthcare, energy, biotechnology, information technology, and national security. It is widely felt that nanotechnology will be the next Industrial Renovation. The prefix "nano" from nanotechnology is a Greek word "nanos" means "little old man or dwarf". Nanotechnology is nothing but the fundamental understanding about how materials react or works at nano scale (i.e. at atomic, molecular or subatomic level) in the creation and utilization of structures, devices and systems that have novel properties and functions. Nanotechnology deals with manipulation of structures of matter in the size range of 1100 nanometers $\left(10^{-9}\right.$ of meter $)$ approximately [1-7].

\section{History of nanotechnology}

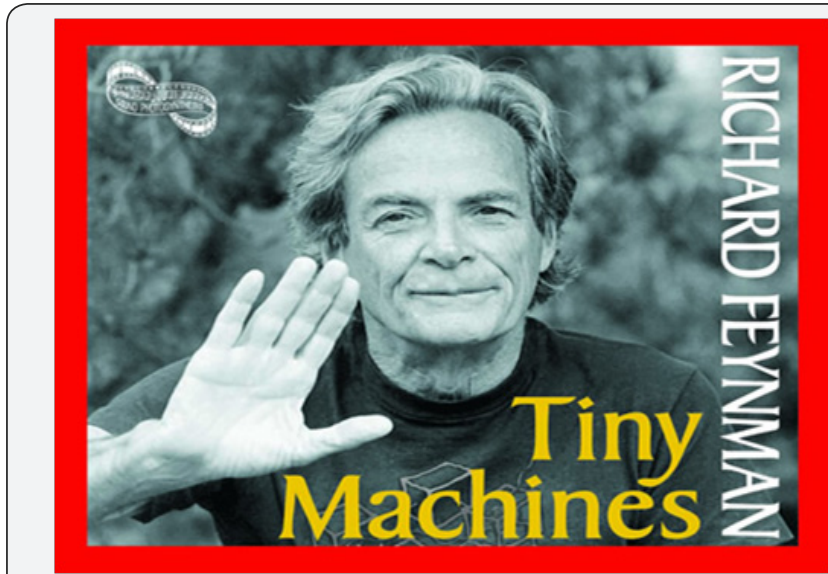

Figure 1

To gain a proper understanding of nanotechnology and its uses in medicine we must first learn about the history of this field of science. Nanotechnology is the science of all things small, down to the atomic scale. It was first thought of by famous physicist Richard Feynman (Figure 1). In 1959 he published his thoughts on the ability to manipulate individual atoms and molecules for the first time at the American physical society at the California Institute of Technology. Feynman now set two challenges. The 
first involved the construction of a nano motor [8]. The second challenge was to reduce the size of letters of the Britannica encyclopedia, so it could fit on the head of a pin. This established the basis for more research into the field of nano science. The next important stage in the history of nanotechnology is the discovery of the nano scale, if this had not been found then what we know as nanotechnology today might not exist. Therefore, it can be said that bio molecular nanotechnology developed from Moore's law which was introduced in 1965 by Gordon Moore-one of the founders of Intel Corporation. This stated that the number of transistors that fit in a given area doubles every 18 months for the next 10 years. This concept exceeded these 10 years and continued to be used giving rise to much smaller scales such as nanometer. This discovery is extremely important to the field of medicine as it allows us to delicately piece individual atoms together to form a fascinating new generation of diagnostics and treatment to ensure patients receive the best care. Therefore, nanotechnology is the manipulation of matter at an atomic scale of $10^{-9}$ [9]. To give an idea of how small this scale actually is, the diameter of a human hair is 200,000nm. Drexler said "At present, medicine is unable to heal anything. It can help the body heal itself but it can't, for example, take an incision and join the two sides together in such a way that the wound is healed as soon as it closed". This quote explicitly suggest that nanotechnology has a potential use in medicine; however further developments are needed to ensure it's completely safe and reliable for patients. Nanotechnology may also help diagnosing cancer earlier with more certainly. Dexler mentioned that "The immune system may not be able to recognize that a cancer cell is abnormal, because it's not able to look at enough different characteristics to identify the cell properly. If injected into the body, a nano machine with an on-board computer could look at 20 different characteristics of a cell before doing anything to it". If this method of diagnosis becomes successful, nanotechnology can be the next innovation in medicine [10].

\section{Applications of Nanotechnology in Various Field}

Nanotechnology includes various aspects in our daily life, such as cryonics, medicine (diagnostics, drug delivery, tissue engineering), environment (filtration), energy (reduction of energy consumption, increasing the efficiency of energy production), information and communication (memory storage, novel semiconductor devices, novel optoelectronic devices, displays, quantum computers). It also helps in heavy industry (aerospace, catalysis, construction, vehicle manufacturers), consumer goods (nano foods, household, optics, textiles, cosmetics, agriculture, sports) [11].

\section{Nanotechnology and dermatology}

The word Nanotechnology has already taken the world by surprise and is still surprising the people by making its existence by including itself in several other fields. In this study, we are focusing on application nanotechnology in dermatological preparation as many people nowadays are not aware of this interesting technology. Skin is the first point of contact for various environmental nanomaterials, be they airborne or solid. Thus, for dermatology, risks of nanomaterials include irritant or allergic contact dermatitis, as well as the potential to develop unanticipated reactions from of whole new classes of irritants, allergens, haptens, cross-reactants and particle-particle interactions that may lead to disease. Nasir Adnan in his article entitled "Nanotechnology And Dermatology" specified some important area of interest in nanodermatological studies, such as; nanobiology, photoprotection (Figure 2), nanocosmetics (Figure 3), nanoimmunology, cosmeceuticals, photonanotherapy, nanodiagnosis, nanocarcigonesis and nanodrug delivery.
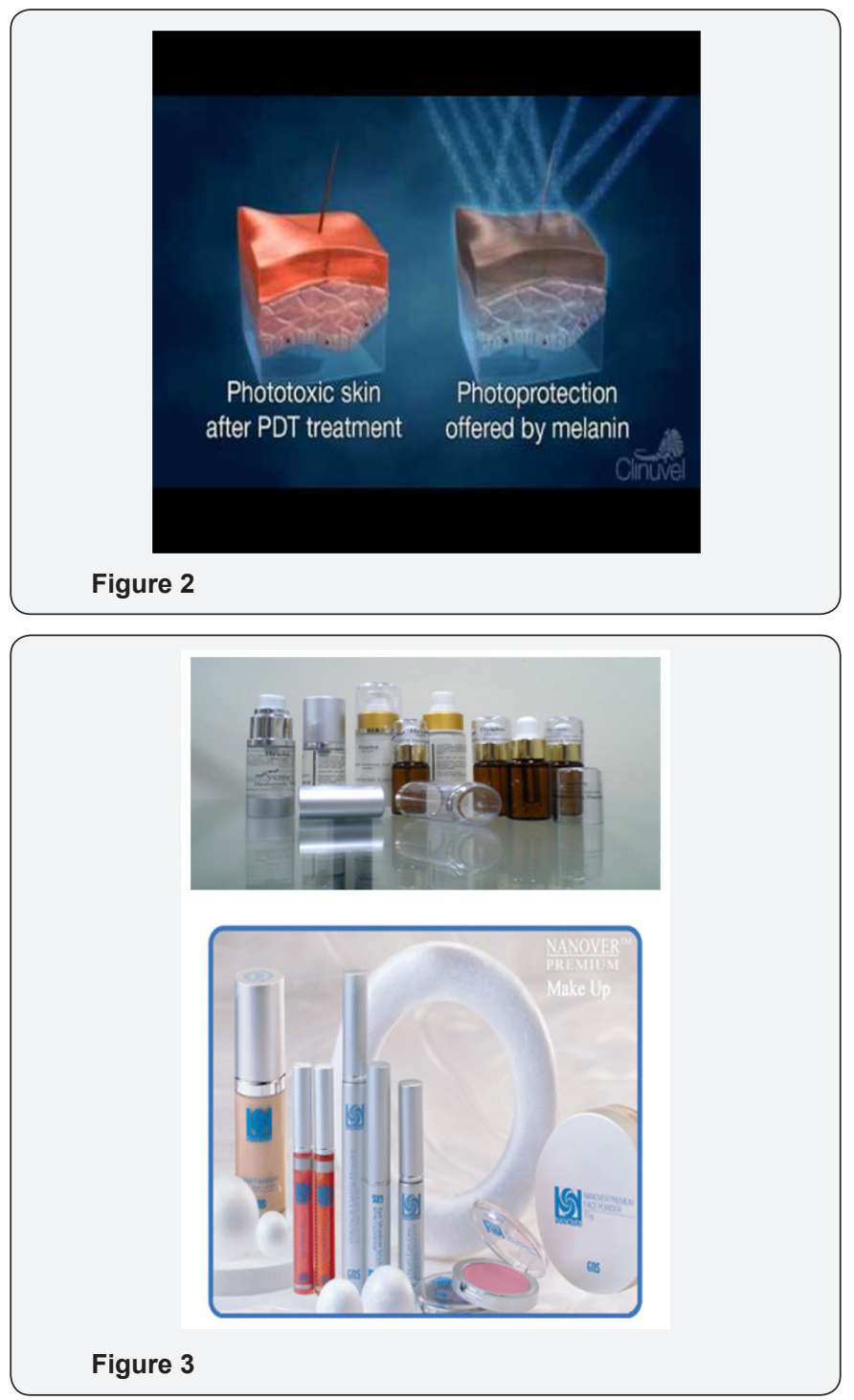

\section{Photoprotectio}

Since UV-radiation and sun exposure have been linked with the increased rate of epithelial skin cancer and melanoma, sunscreens play a critical role in prevention of skin cancer. Sunscreens are vital part of cosmetic anti-aging products. 
At present three photo protecting methods exist that are antioxidants, repair mechanisms stimulators and physical photon blockers. Organic chemical compounds like titanium dioxide ( $\mathrm{TiO} 2)$ and zinc oxide ( $\mathrm{ZnO}$ ) at nano scale are capable to adsorb, disperse, or reflect UV-radiation. There are enough evidences that although nanoparticles can penetrate into the upper regions of human hair follicle or the superficial layers of the stratum corneum, they cannot penetrate the barrier of intact skin and reach the viable epidermis. Quantum dot nano particles are similar in size to that of particles in sunscreen formulation $(30 \mathrm{~nm})$, it stimulate the behavior of TiO2 nano particles after cutaneous application on UV-exposed skin [12-14]. Depending on their size and surface chemistry, a penetration into the viable epidermis and dermis has been shown raising safety concerns, other nano particulate structures such as liposome or solid lipid nanoparticle have been used in sunscreen formulation as penetration enhancers which also improve stability and tolerance for the active moiety [15-19].

\section{Nanodiagnostic}

Number of particles has currently been tested in new diagnostic application due to certain advantages such as the higher sensitivity of related detection methods, which allow performing analysis on small amounts of tissue samples. For examples gold nanoparticles, quantum dots (Figure 4), nanoparticles with magnetic properties and super paramagnetic nanoparticles [20-22].

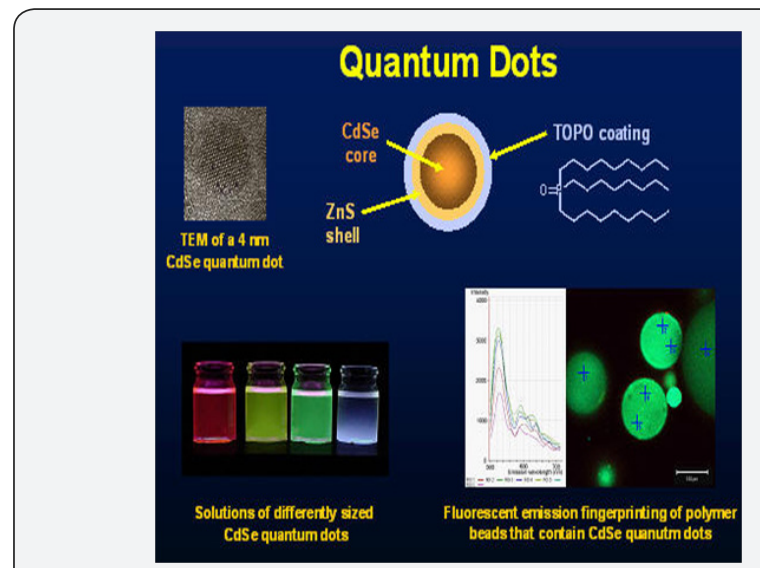

Figure 4

\section{Nanomedicine}

One of the earliest nanomedicine applications was the use of nanocrystalline silver which is as an antimicrobial agent for the treatment of wounds. A nanoparticle cream has been shown to fight staph infections. The nanoparticles contain nitric oxide gas, which is known to kill bacteria. Studies on mice have shown that using the nanoparticle cream to release nitric oxide gas at the site of staph abscesses significantly reduced the infection. Burn dressing that is coated with nanocapsules containing antibiotics. If an infection starts the harmful bacteria in the wound causes the nanocapsules to break open, releasing the antibiotics. This allows much quicker treatment of an infection and reduces the number of times a dressing has to be changed. A welcome idea in the early study stages is the elimination of bacterial infections in a patient within minutes, instead of delivering treatment with antibiotics over a period of weeks.

\section{Therapy technique}

\section{GOLD BUCKYBALLS}

Northwest scientists have created the first golden buckyball - a sub-microscopic "hollow cage" made out of a dozen or so gold atoms. The first buckyball, made of 60 carbon atoms and discovered in the $1980 \mathrm{~s}$, paved the way for much of today's enthusiasm for nanotechnology. The researchers used lasers to vaporize gold and study tiny clusters of atoms. Only clusters of 16-18 gold atoms formed the hollow cages.

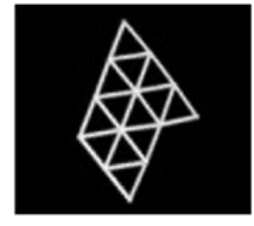

FLAT

15 atoms or smaller

Source: Proceedings of the Nation

Figure 5

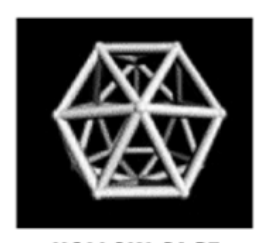

HOLLOW-CAGE

15-18 atoms

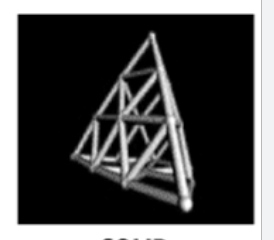

SOLID

18 atoms or more

\section{}
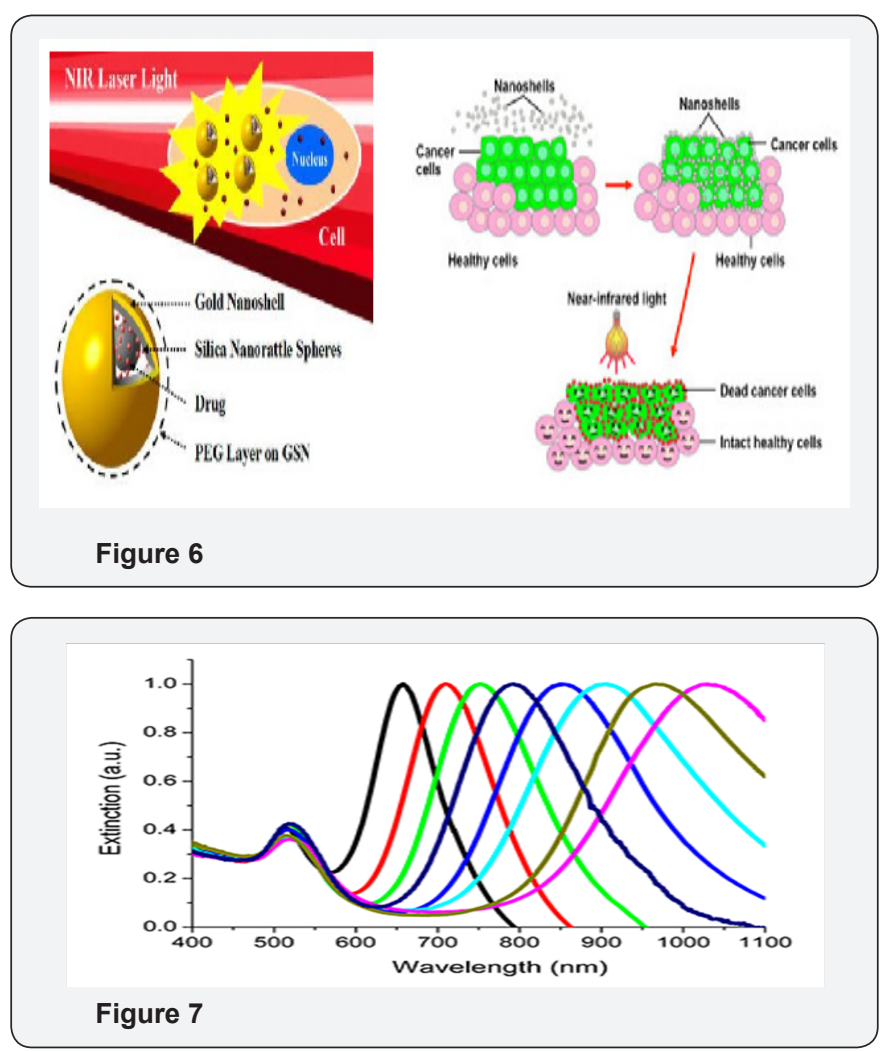

Bucky balls (Figure 5) may be used to trap free radicals generated during an allergic reaction and block the inflammation that results from an allergic reaction. Nanoshells (Figure 6) may be used to concentrate the heat from infrared light to destroy cancer cells with minimal damage to surrounding healthy 
cells. Nanospectra Biosciences (Figure 7) has developed such a treatment using nanoshells illuminated by an infrared laser that has been approved for a pilot trial with human patients. Nanoparticles, when activated by x-rays that generate electrons that cause the destruction of cancer cells to which they have attached themselves. This is intended to be used in place radiation therapy with much less damage to healthy tissue. Nanobiotix has released preclinical results for this technique. Aluminosilicate nanoparticles can more quickly reduce bleeding in trauma patients by absorbing water, causing blood in a wound to clot quickly. Z-Medica is producing medical gauze that uses aluminosilicate nanoparticles. Stimulate an immune response to fight respiratory viruses [23].

\section{Nanodrug delivery}

The use of nanotechnology in medicine and more specifically drug delivery is set to spread rapidly. However, one of the major challenges in drug delivery is to get the drug at the place it is needed in the body thereby avoiding potential side effects to non-diseased organs. This is especially challenging in cancer treatment where the tumor may be localized as distinct metastases in various organs. The non restricted cytotoxicity of chemotherapeutics thus limits the full use of their therapeutic potential. Local drug delivery or drug targeting result in increased local drug concentrations and provides strategies for more specific therapy. Nanoparticles have specific particles as tools to enable these strategies. These include benefits such as their small size which allows penetration of cell membranes, binding and stabilization of proteins, and lysosomes escape after endocytosis. The entrapment of chemotherapeutics in nanosized formulations like liposomes has been already subject of study for considerable time [24-25]. In addition, toxicity effect has also been investigated as there are several expert reports about nanoparticle toxicity have been reported. However, one cannot rely on the toxicological profile of the bulk material when that material is used in a nanoformulation. What is clear is that the safety evaluation and the risk benefit analysis need to be performed on a case by case basis to avoid any toxicity effect [26].

\section{Advantages of Nanotechnology}

Since Feynman's and Drexler's time, nanotechnology has made great strides. Consumer products such as sunscreens, shampoos, and cosmeceuticals have been developed. Diagnostic devices and tools are in the early stages of development and treatments for variety of skin diseases are being explored in the laboratory [27].

\section{Consumer product}

Sunscreens is a lotion, spray, gel or other topical product that absorb or reflects some of the sun's ultraviolet (UV) radiation on the skin exposed to sunlight and thus helps protect against sunburn [28]. A number of manufacturers have been developed sunscreens using nanosized titanium, zinc, and iron to allow formulation in vanishing and cosmetically elegant vehicles. Retinoids suffer from instability and irritability. Nano encapsulated retinoids are more stable and their release can be controlled and slowed, resulting in less irritation. Solid lipid nanoparticles and nanostructured lipid carriers can be synthesized with an active ingredient in the center of the particle to delay release. Slow release kinetics are important for perfumes, which can yield all-day fragrance [29]. They also useful for insect repellents, such as N, N-Diethyl-meta-toluamide (DEET) (Figure 8), to prolong efficacy. Fabrics incorporating super hydrophobic 'nanowhiskers' (nanosized hair-like projections on individual textile fibers) can repel stains, dirt, and microorganisms. Bulk silver is inert. Silver on the nanoscale is highly toxic to microorganisms, including resistant microorganisms such as staphylococcus aureus [30,31]. Fabrics impregnated with nanosilver are antimicrobial and helpful to health care workers. Nanosilver is also being included into dressings or bandages to minimize the potential for wound infection. Nanosilver in washing machines allows disinfection at lower temperatures and saves energy.

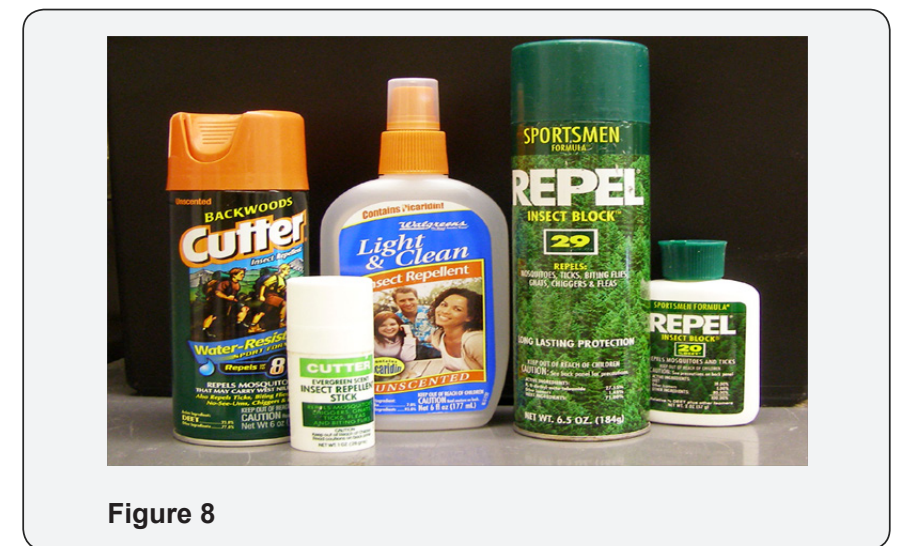

\section{Therapeutic agents}

Epicutaneous drug delivery is one of the great areas for advance in dermatologic disease. Some agent developd by nanotechnology will be recognizable, but some will defy and completely upend our current methods of dermatologic therapy. Drugs encapsulated in polymers or nanoparticles will be stabilized, and their release and activity also being targeted. Besides, biologically active forms of trapped nanoparticulate volatile antimicrobial gases such as nitric oxide have shown utility in the treatment of skin infections and have proven highly effective at penetrating abscesses [32]. Encapsulated topical steroids are being developed, which accumulate in the epidermis, but do not penetrate the dermis. These types of agents will be helpful in management of spongiotic dermatoses. They also can reduse the risk of corticosteroid-mediated sideeffects. Bulk soybean oil is not toxic. Nanoemulsions (Figure 9) of soybean oil are antimicrobial and are being incorporated into disinfectants. Recently, nanoemulsions of other compounds 
that can penetrate the nail and the pilosebaceous unit are used to treat onychomycosis (fungal infections on nail) and acne. Polymeric nanoparticles encapsulating small inhibitor ribonucleic acids (siRNAs) can selectively in activate gene expression. Nanoencapsulated siRNAs have been used for the treatment of genodermatosis (skin condition of genetic origin) [33] and for the successful targeted delivery and inhibition of a test gene expressed in melanoma in human trials [34]. Thermosensitive polymers encapsulated drug below a critical temperature and dissolve to release the drug above the critical temperature. These are used for drug delivery at sites of inflammation and being developed to target release wherever external heat is applied. Topical nanoparticles can be engineered to elicit humoral and cell-mediated immunity [35,36]. Micro needle patches have been shown to painlessly target delivery of vaccines to the epidermis and reticular dermis, where the bulk of Langerhans cells and dermal dendritic cells reside, inducing a potent immune response [37-38].

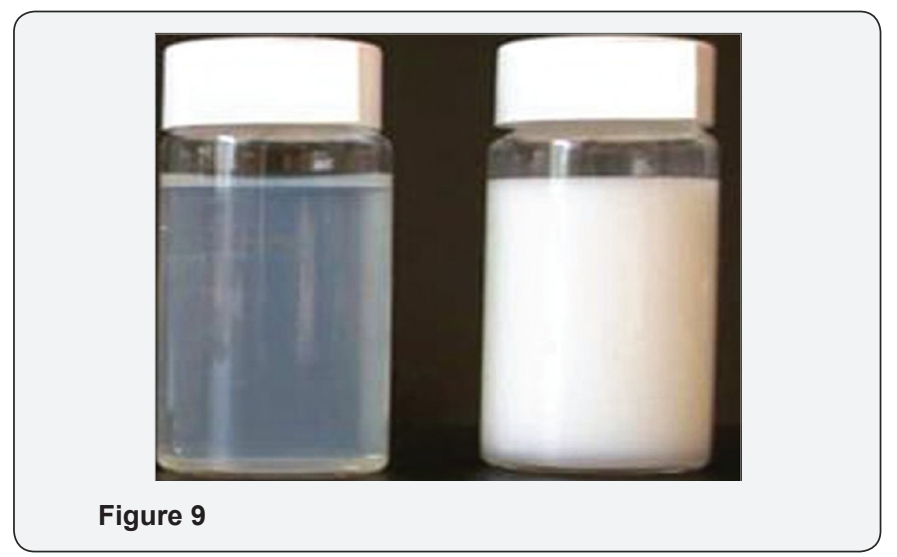

\section{Diagnostic devices}

The primacy of examination in diagnosis is one of the interesting parts of dermatology. Most skin conditions reveal themselves to astute and informed observation. However, dermatologists still use specialized tools and tests to assist in or confirm the diagnosis of skin disease. The tools of the nanotechnology era will bear little resemblance to our potassium hydroxide slide preparation and will be far less invasive than our punch biopsy. Quantum dots are small semiconductors $[39,40]$. They absorb desired wavelengths of light, and then emit brightly fluorescent color. Quantum dots can be coupled to tags such as antibodies. In animal models, without using radioactivity, tagged fluorescent quantum dots able to visualize tumors in the skin and can produce sentinel lymph nodes [41]. A nanopunch is a small, simple biopsy tool consisting of copper, nickel, silicon and chromium layered in the shape on an origami claw. Differing coefficients of expansion of the layers allow temperature change to cause the claw to close and open, like a Venus flytrap. The nanopunch is paramagnetic and its migration can be controlled by a magnetic field. It could be injected into bloodstream and guided to challenging biopsy sites, such as the nail matrix, the fascia, and the liver. The claw could be activated by temperature and collected from a urine sample by magnetic trap. Tissue could then be released for analysis. Carbon nanotubes conduct electricity, unlike their bulk precursors. It can be coupled to macromolecules such as nucleic acids and antibodies. Coupled molecules alter the conductivity of the carbon nanotube as compared with its native state. Conductivity is further altered if the coupled molecules bind their cognate receptors. Its conductivity can also be used to make a highly sensitive biomarker sensor on an extremely tiny scale (sub-organellar). Single biomarkers or tandem arrays may be useful for the real time diagnosis of skin infections and possibly malignancies. Carbon nanotube sensors may be able to detect infinitesimally minute quantities of substrate.

\section{Disadvantages of Nanotechnology}

Despite the possibilities and the advancements that the nanotechnology offers to the world, there also exist certain severe discussions on the prevalence of the nanotechnology in the world. Many of the people in the world are aware of the advancements that various field have made since the introduction of nanotechnology into the world. But little do they know of the hidden dangers and potential risks involved with nanotechnology running under the carpet. Most technologies have their own advantages and disadvantages. So do the nanotechnology, which also causing some bad effect to human especially. The most serious problem with nanoparticles is cytotoxicity. Cytotoxicity can be caused by the particles being contaminated by harmful or poisonous products. The chances of such contamination increase as nanoparticles are being manufactured on a large scale. Therefore, instead of nanoparticles being useful to the body, it has the opposite effects.

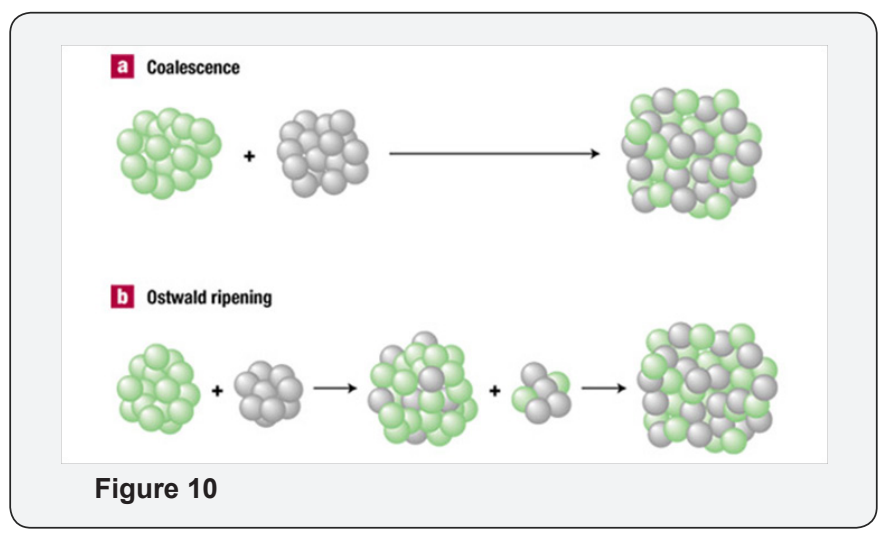

Next, the costs when using nanotechnology are very high because the product is fully made of molecules. It is very difficult to produce such extravagant items, even if they could potentially give a long lasting treatment for patients. Moreover, the maintenance cost is high. The damage of the nanotechnology product may cause not recover the original product, and it will be wasted. The only problem of instability of nanoemulsion can arise by the Ostwald ripening (Figure 10). The instability of 
nanoemulsion is due to some main factors including creaming flocculation, coalescence and Ostwald ripening. Among them Ostwald ripening is the main mechanism of nanoemulsion instability because rest of the problem are minimized by the small size of nanoemulsion and use of nonionic type of surfactant. In Ostwald ripening small droplets with high radius of curvature converted into large droplets with low radius of curvature. Two droplets diffuse and become one large droplet. Thus, after the storage for a long time period, droplets size distribution shifted to large sizes and the transparency of nanoemulsion become turbid. It is also identified that Ostwald ripening creates a problem during the delivery of formulations. Several theories have been suggested for the demonstration of Ostwald ripening. Creaming of nanoemulsion is prevented by the faster diffusion rate of smaller droplets. Vanderwall force is responsible for the attraction of droplets and leads to the flocculation of emulsion. But in case of nanoemulsion nonionic surfactant, it does not create any kind of attractive force, hence no flocculation occurs. The droplet size of nanoemulsion also prevents the flocculation because these small drop-lets show high curvature and Laplace pressure opposes the deformation of large droplets.

\section{Conclusion}

Discovery of Nanotechnology is indeed a revolution in the field of medicine and in medical practice as well but at the same time it is not easy to say that the impact of nanotechnology on world is positive only. If we consider about the expenses, the investment is very high and therefore not affordable for small scale manufacturers. The chances of loss is greater than the profits as if there is a failure or damage of product while researching, manufacturing, transporting or delivering, there will be huge loss. So, it takes full of risk and need to be considered wisely. In midst of all these, it is very difficult to decide on the merits and demerits of the Nanotechnology. On one side, the Nanotechnology provides an amazing base for the world to advance in many of the key areas and on the other side, it itself poses as a potential risk by elaborating the possibilities of destruction of the whole world. Hence we can say that nanotechnology is definitely a boon but depends on how wisely and properly it has been utilized as if the caution has not been made it will be a curse too.

\section{Reference}

1. Ochekpe NA, Olorunfemi PO, Ngwuluka NC (2009) Nanotechnology and Drug Delivery Part 1: Background and Applications. Tropical Journal of Pharmaceutical Research 8(3): 265-274.

2. Stylios GK, Giannoudis PV, Wan T (2005) Application of Nanotechnologies in medical practice. Injury 36 (Suppl1): S6-S13.

3. The Royal Society and the royal Academy of Engineering (2004) Nanosceince and Nanotechnologies. The royal society and the royal Academy of Engineering Report.

4. Parveen S, Misra, R, Sahoo SK (2012) Nanoparticles: a boon to drug delivery, therapeutics, diagnostics and imaging. Nanomedicine $8(2): 147-166$.
5. Sahoo SK, Parveen S, Panda JJ (2007) The present and future of nanotechnology in human health care. Nanomedicine 3: 20-31.

6. Sahoo SK, Labhasetwar V (2003) Nanotech approaches to drug delivery and imaging. Drug Discovery Today 8(24): 1112-1120.

7. Bhushan B et al. (2012) Nano Encyclopedia of nanotechnology. 90(481):9751-9754.

8. Svedberg T, Nichols JB (1923) Determination of the size and distribution of size of particle by centrifugal methods. J Am Chem Soc 45(12): 2910-2917.

9. Iijima S, Ichihashi T (1993) Single-shell carbon nanotubes of 1-nm diameter. Nature 363: 603-605.

10. http://www.foresight.org/nano/history.html.

11. Hillie T, Hlophe M (2007) Nanotechnology and the challenge of cleanwater. Nature Nanotechnology 2: 663-664.

12. Cross SE Innes B, Roberts MS, Tsuzuki T, Robertson TA, et al. (2007) Human skin penetration of sunscreen nano particles: in-vitro assessment of a novel micronized oxide formulation. Skin Pharmacol Physiol 20(3): 148-154.

13. Lademann J, Weigmann H, Rickmeyer C, Barthelmes H, Schaefer H, et al. (1999) Penetration of Titanium dioxide microparticles in a sunscreen formulation into the horny layer and the follicular orifice. Skin Pharmacol Appl Skin Physiol 12(5): 247-256.

14. Newman MD, Stotland M, Ellis JI (2009) The safety of nano sized particles in titanium dioxide and zinc oxide-based sunscreens. J Am Acad Dermatol 61(4): 685-692.

15. Mortensen LJ, Oberdörster G, Pentland AP, Delouise LA (2008) In vivo skin penetration of quantum dot nano particles in the murine model: the effect of UVR. Nano Lett 8(9): 2779-2787.

16. Durand L, Habran N, Henschel V, Amighi K (2010) Encapsulation of ethylhexyl methoxycinnamate, a light-sensitive UV filter, in lipid nanoparticles. J Microencapsul 27(8): 714-725.

17.Xia Q, Saupe A, Müller RH, Souto EB (2007) Nano structured lipid carriers as novel carrier for sunscreen formulation. Int J Cosmet Sci 29(6): 473-482.

18. Alvarez RR, Barré G, Guy RH, Fessi H (2001) Biodegradable polymer nano capsules containing a sunscreen agent: preparation and photo protection. Eur J Pharm Biopharm 52(2): 191-195.

19. Padamwar MN, Pokharkar VB (2006) Development of vitamin loaded topical liposomal formulation using factorial design approach: drug deposition and stability. Int J Pharm 320(1-2): 37-44.

20. Ballou B, Ernst LA, Andreko S, Harper T, Fitzpatrick JA, et al. (2007) Lymph node imaging using quantum dots in mouse tumor models. Bioconjug Chem 18(2): 389-396.

21. Jain KK (2005) Nanotechnology in clinical laboratory diagnostics. Clin Chim Acta 358(1-2): 37-54.

22. Olafsson R, Bauer DR, Montilla LG, Witte RS (2010) Real-time contrast enhanced photo acoustic imaging of cancer in a mouse window chamber. Opt Express 18(18): 18625-18632.

23. http://www.understandingnano.com/medicine.html

24. Crommelin DJ, Storm G (2003) Liposome: from the bench to bed. J Liposome Res 13(1): 33-36.

25. Metselaar JM, Gert S (2005) Liposome in the treatment of inflammatory disorder. Expert opinion on drug delivery 2(3): 465-476.

26. Minko T, Pakunlu RI, Wang Y, Khandare JJ, Saad M (2006) New generation of liposomal drug for cancer. Anticancer agent med Chem 6(6): 537-552. 
27. De JWH, Borm PJ (2008) Drug delivery and nanoparticles: application and hazards. Int J Nanomedicine 3(2): 133-149.

28. Van OMH, Ros WJ, Eland de KPC, Kennedy C, Thio BH (2007) Effectiveness of the nursing programme 'Coping with itching': a randomized controlled study in adults with chronic pruritic skin disease. Br J Dermatol 156(6): 1235-1244.

29. Moyal D, Fourtanier A (2008) Broad-spectrum sunscreens provide better protection from solar ultraviolet-simulated radiation and natural sunlight-induced immuno suppression in human beings. Journal of the American Academy of Dermatology 58(5): S149-S154.

30. Dykes PJ, Marks R (1979) An appraisal of the methods used in the assessment of atrophy from topical corticosteroids. Br J Dermatol 101(5): 599-609.

31. Yosipovitch G, Papoiu AD (2008) What causes itch in atopic dermatitis? Curr Allergy Asthma Rep 8(4): 306-311.

32. Papoiu AD, Yosipovitch G (2010) Topical capsaicin. The fire of a 'hot' medicine is reignited. Expert Opin Pharmacother 11(8): 1359-1371.

33. Imamachi N, Park GH, Lee H, Anderson DJ, Simon MI (2009) TRPV1expressing primary afferents generate behavioral responses to pruritogens via multiple mechanisms. Proc Natl Acad Sci 106(27) 11330-11335.

34. Andoh T, Nishikawa Y, Yamaguchi MT, Nojima H, Narumiya S (2007)
Thromboxane A2 induces itch-associated responses through TP receptors in the skin in mice. J Invest Dermatol 127(8): 2042-2047.

35. Szepietowski JC, Szepietowski T, Reich A (2005) Efficacy and tolerance of the cream containing structured physiological lipids with endocannabinoids in the treatment of uremis pruritis: a preliminary study. Acta Dermatovenerol Croat 13(2): 97-103.

36. Eberlein B, Eicke C, Reinhardt HW, Ring J (2008) Adjuvant treatment of atopic eczema: assessment of an emollient containing $\mathrm{N}$-palmitoylethanolamine (ATOPA study). J Eur Acad Dermatol Venereol 22(1): 73-82.

37. Stander S, Reinhardt HW, Luger TA (2006) Topical cannabinoid agonists. An effective new possibility for treating chronic pruritis. Hautarzt 57(9): 801-807.

38. Patel T, Ishiuji Y, Yosipovitch G (2007) Nocturnal itch: why do we itch at night? Acta Derm Venereol 87(4): 295-298.

39. Davis MP, Frandsen JL, Walsh D, Andresen S, Taylor S (2003) Mirtazapine for pruritis. J Pain Symptom Manage 25(3): 288-291.

40. Steinhoff M, Neisius U, Ikoma A, Fartasch M, Heyer G (2003) Proteinaseactivated receptor- 2 mediates itch: a novel pathway for pruritis in human skin. J Neurosci 23(15): 6176-6180.

41. Wood GJ, Akiyama T, Carstens E, Oaklander AL, Yosipovitch G (2009) An insatiable itch. J pain 10(8):792-797.

\begin{tabular}{l} 
Your next submission with Juniper Publishers \\
will reach you the below assets \\
- Quality Editorial service \\
- Swift Peer Review \\
- Reprints availability \\
- E-prints Service \\
- Manuscript Podcast for convenient understanding \\
- Global attainment for your research \\
- Manuscript accessibility in different formats \\
( Pdf, E-pub, Full Text, Audio) \\
- Unceasing customer service \\
Track the below URL for one-step submission \\
https://juniperpublishers.com/online-submission.php \\
\hline
\end{tabular}

